\title{
Prácticas educativas en movimientos sociales de América Latina
}

\author{
Educational Practices in Latin American Social Movements \\ Práticas educativas nos movimentos sociais da América Latina
}

Alfonso Torres Carrillo ${ }^{1}$

\section{Resumen}

El artículo presenta un análisis de cuatro propuestas educativas gestadas por movimientos sociales y procesos populares en América Latina. Tomando como referente la sistematización de cada una de estas, se hace una lectura transversal de los sentidos y prácticas más significativos con respecto a algunas dimensiones de su acción educativa, tales como su organicidad e identidad política, sus sujetos educativos, sus influencias pedagógicas, finalidades formativas, contenidos curriculares, metodologías de trabajo, producción de conocimiento y sostenibilidad. Finalmente, se hace un balance reflexivo sobre las tensiones y los desafíos de las prácticas educativas en los movimientos sociales.

\section{Palabras clave}

movimientos sociales; práctica educativa; educación popular; pensamiento crítico

\section{Abstract}

This paper analyzes four educational proposals originated by social movements and popular processes in Latin America. The systematization of each of these proposals operates as a cross-reading of the most relevant senses and practices related to some aspects of their educational action, such as their consistency and political identity, their educational subjects, their pedagogical influences, their formative purposes, their curricular content, their working methodology, their production of knowledge and sustentability. Finally, a reflection is made about the tensions and challenges of the educational practices of social movements.

\section{Keywords}

social movements; educational practice; popular education; critical thinking

\section{Resumo}

0 artigo apresenta uma análise de quatro propostas educativas gestadas pelos movimentos sociais e processos populares na América Latina. Tendo como referência a sistematização de cada uma dessas, foi realizada uma leitura transversal das práticas e os sentidos mais significativos com relação a algumas dimensões de sua ação educativa, como sua organicidade e identidade política, seus sujeitos educativos, suas influências pedagógicas, finalidades formativas, conteúdos curriculares, metodologias de trabalho, produção de conhecimento e sustentabilidade. Finalmente, realiza-se um balanço reflexivo sobre as tensões e os desafios das práticas educativas nos movimentos sociais.

Palavras chave

movimentos sociais; prática educativa; educação popular; pensamento crítico

Artículo recibido el 5 de noviembre del 2016 y aprobado el 21 de diciembre del 2016

1 Universidad Pedagógica Nacional, Bogotá, Colombia. Correo electrónico: atorres@pedagogica.edu.co 


\section{Presentación}

Dentro del actual ciclo de movilización colectiva en América Latina (1994-2016), un hecho que llama la atención es la creciente importancia que los movimientos sociales dan a los temas educativos, ya sea porque generan instancias y espacios educativos o porque reconocen el carácter formativo de sus propias dinámicas. $\mathrm{Al}$ mismo tiempo, ha sido creciente el interés por parte del campo de la investigación educativa de abordar, para comprender, las especificidades y las potencialidades pedagógicas de dichas prácticas educativas.

En el grupo de investigación Sujetos y Narrativas en Investigación y Enseñanza de las Ciencias Sociales de la Universidad Pedagógica Nacional de Colombia, nos hemos venido ocupando del tema desde hace dos décadas. En ese lapso hemos realizado investigaciones en torno a lo educativo, lo formativo y lo pedagógico en organizaciones populares y otras expresiones de acción colectiva (Torres, 1995; Barragán, Mendoza y Torres, 2006; Aguilera, González y Torres, 2014; Aguilera y González, 2014).

El presente artículo aborda algunos rasgos característicos de las acciones educativas gestadas por algunos movimientos y procesos sociales de América Latina. Toma como referente los resultados de dos investigaciones recientemente desarrolladas con el grupo de investigación ${ }^{2}$, las cuales permitieron un acercamiento "desde adentro" de las experiencias. A partir de la combinación de estrategias conversacionales, de indagación documental y de observación participativa caracterizamos estas iniciativas educativas y de formación, para después hacer un análisis y una interpretación transversal de sus aspectos más relevantes.

Los espacios o procesos formativos y los movimientos $\mathrm{u}$ organizaciones correspondientes fueron:

1. La Coordinadora de Bachilleratos Populares en Lucha: espacio de coordinación y acción de centros educativos para adultos y jóvenes

2 Dichos proyectos fueron: 1) “Educación en movimientos sociales latinoamericanos", Proyecto FHU-292-11 (2011-2012), y 2) “Formación de subjetividades, sentidos de comunidad y alternativas políticas en procesos organizativos locales", Proyecto Dcs-362-13 (2013-2015). de la ciudad y la provincia de Buenos Aires. Estos están articulados a fábricas recuperadas y otros procesos organizativos surgidos a partir de la crisis económica y social de Argentina desde el 2001.

2. La Escuela Nacional de Formación (Enfoc) de la Confederación Nacional de Trabajadores Agrarios (Contag): propuesta de formación sindical creada desde el 2005 por este movimiento de trabajadores rurales de Brasil que agrupa y moviliza a los pequeños productores $\mathrm{y}$ asalariados rurales de dicho país.

3. La Universidad Intercultural Amawtay Wasi: gestada por la Confederación Nacional de Organizaciones Indígenas del Ecuador (Conaie) y aprobada por el Congreso de la República del Ecuador en el 2004 frente a la necesidad de una formación superior fundamentada y organizada conforme a las cosmovisiones culturales de los pueblos ancestrales.

4. La Corporación Comunitaria Convivamos y su "Programa de Pedagogía Comunitaria". Esta organización popular surge a comienzos de la década de los noventa en una de las zonas populares de Medellín (Colombia) más afectadas por la violencia, y busca el fortalecimiento comunitario y organizativo de la población a partir del desarrollo de programas educativos, de desarrollo local, de derechos humanos y de comunicación alternativa.

En los cuatro casos, se trata de prácticas educativas con algún grado de estructuración y continuidad, ya sea que asuman la forma de universidades, escuelas secundarias, programas o escuelas de formación. Con base en la caracterización de cada una de ellas, presentamos algunos rasgos característicos de su acción pedagógica, como su organicidad e identidad, sus sujetos y relaciones educativas, sus influencias pedagógicas, sus finalidades formativas, sus contenidos curriculares, sus metodologías de trabajo, su producción de conocimiento y su aporte a la formación de pensamiento crítico. Finalmente, haré un balance 
reflexivo sobre la sostenibilidad y los desafíos de las propuestas educativas en los movimientos sociales.

\section{Organicidad e identidad política de las propuestas educativas}

En todos los casos, las propuestas educativas surgen como una "necesidad" y un "desafío" del movimiento social, ya sea para formar a las comunidades en los valores del movimiento y las epistemologías ancestrales (Amawtay Wasi); para socializar entre las bases sus orientaciones políticas (Enfoc); para generar y socializar conocimientos y saberes pertinentes a las estrategias y finalidades del movimiento; para generar organización de base desde el derecho a la educación (bachilleratos populares territoriales) y para acompañar la formación de los sujetos que participan en la organización (Convivamos).

En la medida en que las iniciativas educativas surgen y se construyen como resultado de una decisión política del movimiento, también asumen como propósito fortalecer sus principios y programas, ya sea los mandatos del movimiento indígena (Amawtay Wasi), el proyecto alternativo de desarrollo rural sustentable y solidario (la Enfoc) o el fortalecimiento de la autonomía de las organizaciones de base (bachilleratos, Convivamos).

Algunos, como los bachilleratos populares, "son pensados como organizaciones sociales impulsadas y diseñadas según las necesidades y estrategias socioeducativas de la propia comunidad territorial y de los movimientos sociales responsables en su implementación" (Ampudia, 2012, p. 45). Al reconocerse como "organizaciones sociales", también expresan su potencial para articularse y convertirse en un movimiento con identidad propia. Al mismo tiempo, los bachilleratos populares expresan nuevas formas autogestionarias de organización popular y fueron tomados como estrategia educativa por casi todos los movimientos sociales existentes en Argentina (Ampudia y Elisalde, 2014, p. 28).

Un segundo rasgo que define la identidad de las propuestas educativas analizadas es que también justifican su emergencia a partir de la crítica radical al sistema capitalista, a la educación tradicional y al sis- tema escolar. Para los integrantes y responsables de los bachilleratos populares no hay proyecto pedagógico sin proyecto político antiburocrático, anticapitalista y que reivindique una democracia de base en el campo educativo (Ampudia y Elisalde, 2014, p. 30). En sus discursos, es frecuente la referencia a que en los bachilleratos se trata de "desnaturalizar las relaciones capitalistas" (Sverdlick y Costas, 2008).

Los movimientos campesino e indígena analizados, al igual que la organización popular, también asumen que los problemas que abordan obedecen a factores estructurales ocasionados por el sistema capitalista y colonial impuesto en la cultura, tanto en el campo como en la ciudad. Por eso estas propuestas pedagógicas buscan identificarse como una política crítica y alternativa al orden instituido, capaz de construir nuevas formas de participación y democracia.

En cuanto a la educación hegemónica, la Enfoc cuestiona los estilos autoritarios, verticales e instrumentales predominantes en la educación sindical. Por su parte, los bachilleratos populares critican al sistema educativo neoliberal que expulsa de la escuela a miles de jóvenes pobres. A su vez, la Universidad Amawtay Wasi toma distancia radical de la educación institucional, por su carácter colonial y eurocéntrico que desconoce las realidades y las culturas de los pueblos indígenas.

En fin, vemos cómo el carácter inicial y la identidad que asumen las propuestas educativas de los movimientos son principalmente políticos, es decir, se subordinan, buscan ser coherentes y potencian las orientaciones, finalidades y programas políticos de los movimientos, a la vez que toman distancia crítica frente a los sentidos, ideologías y valores predominantes en la sociedad que buscan transformar.

\section{Fuentes e influencias pedagógicas de la acción educativa}

Todas las experiencias educativas se identifican y están orientadas por enfoques o construcciones pedagógicas alternativas, en particular por la educación popular. Por ello, hay una explícita imbricación entre lo político y lo pedagógico en un horizonte 
crítico, emancipador y transformador. Tres de las propuestas expresamente asumen los principios políticos y pedagógicos de la educación popular (bachilleratos populares, Enfoc y Convivamos): "La educación del campo está basada en un conjunto de principios pedagógicos inspirados en la educación popular y en Paulo Freire, como lo confirma la declaración final de la II Conferencia Nacional por una Educación del Campo" (Batista, 2010, p. 204).

Para el movimiento popular La Dignidad, perteneciente a la red de bachilleratos populares, su opción es clara:

Apostamos a la construcción de espacios educativos autónomos de nuevas concepciones políticas, educativas y de poder popular. Asumimos la perspectiva de la educación popular, ya que entendemos la práctica educativa como acción política y postulamos una concepción de conocimiento como herramienta para la lucha y para la construcción de una nueva sociedad. (Colectivo Diatriba, 2013, p. 18).

La Corporación Convivamos expresa que en su actuar confluyen cuatro enfoques teórico-metodológicos: de género, de derechos humanos, de desarrollo local y de educación popular (Convivamos, 2011). El último es una estrategia de su programa de acompañamiento comunitario:

Desde este enfoque asumimos a los sujetos como sujetos de saber y transformación, protagonistas de su historia y por ende, responsables de su devenir. Esta mirada posibilita relaciones que van más allá de la transmisión y asunción de conocimientos, hasta la horizontalidad y el respeto, generando iniciativa, autonomía, responsabilidad por los actos cotidianos y disminuyendo así la dependencia. (Corporación Convivamos, 2012, p. 14).

Otras tradiciones de pensamiento y de pedagogías emancipadoras que confluyen en las prácticas educativas de los movimientos sociales latinoamericanos son: las pedagogías socialistas, la teología de la liberación, las pedagogías "do movimiento", en el caso del movimiento campesino de Brasil; incluso, plantean que tienen sus propios enfoques pedagógicos, como la "pedagogia do campo". En el caso de Enfoc, su propuesta educativa también se define como "pedagogía para una nueva sociabilidad" que tiene como fundamento una teoría de la formación humana inspirada en el pensamiento de Freire.

Por su parte, las universidades indígenas reivindican que su principal fundamentación está en sus propias cosmovisiones ancestrales y en las orientaciones políticas de los movimientos en las que surgieron, de profunda raigambre comunitaria. En la Amawtay Wasi hay una sólida reflexión epistemológica basada en la interculturalidad crítica, la episteme ancestral y el saber propio, la cual se expresa en su currículo y en sus metodologías.

En todos los casos, se asumen como pedagogías emancipadoras, que buscan formar sujetos que cuestionen la sociedad capitalista y colonial. Estas opciones pedagógicas alternativas se expresan en la definición de sus principios, criterios y orientaciones pedagógicos generales de cada propuesta educativa. En el caso de las experiencias ligadas a organizaciones urbanas y rurales, hay una construcción explícita de principios políticos y pedagógicos que recogen la tradición educativa popular, adecuándola a su singularidad.

\section{Horizontes de sentido y finalidades formativas}

Como se ha señalado, la emergencia y la perdurabilidad de las iniciativas educativas están asociadas a los grandes propósitos y horizontes de futuro de las organizaciones y los movimientos, por ello los comparten y los promueven. Así, por ejemplo, en la Universidad Amawtay Wasi se le apuesta al buen vivir (Suma Kawsay) como un modo de vida comunitario que no es posible en una sociedad capitalista. Por su parte, la Corporación Convivamos afirma que su acción apunta a garantizar la vida digna de los pobladores, la cual "descansa, por un lado, sobre los valores de justicia social y autonomía; por el otro, por los principios del civilismo, lo popular, la solidaridad y la democracia" (Corporación Convivamos, 2012, p. 23).

Por otro lado, en la medida en que son propuestas educativas, se estructuran como escuelas o universidades, y las orientaciones políticas y pedagógicas se 
traducen en fines y objetivos formativos explícitos. $\mathrm{Su}$ análisis nos permite confirmar su coherencia con los principios expuestos y, a la vez, identificar sentidos emergentes acerca del tipo de procesos que procuran potenciar y de los sujetos que buscan formar.

En primer lugar, hay que señalar que la elaboración de estas intencionalidades recae en manos de los movimientos y comunidades, a través de sus estructuras e instancias de decisión, ya sean cabildos o autoridades propias (en el caso de las universidades indígenas), de las asambleas y de los equipos de educadores (en el caso de la Enfoc y los bachilleratos populares). En segundo lugar, el contenido de los objetivos también está en función de la especificidad de los sujetos educativos (sean el movimiento o las comunidades en su conjunto, sus líderes y cuadros o estudiantes de base).

En términos generales, los fines educativos formulados por las propuestas educativas apuntan simultáneamente a fortalecer los movimientos y sus organizaciones, formar los sujetos para estos, y transformar las subjetividades individuales y colectivas. Un ejemplo de un fin más centrado en el movimiento es el de la Contag, para la cual los objetivos de su Escuela de Formación Política (Enfoc) están subordinados a los del Plan Nacional de Formación y apuntan a transformar dimensiones más organizativas que personales (Contag, 2006, p. 36):

1. Constituir y desarrollar un sistema de formación político-sindical, que valorice el abordaje ideológico y clasista, orientado a atender las demandas de los trabajadores y las trabajadoras en la disputa por el proyecto de sociedad.

2. Construir y desarrollar metodologías que respeten la pluralidad de ideas, la especificidad de los sujetos y posibilite a los educandos y educandas el acceso a diferentes visiones existentes sobre un tema.

3. Estimular el desarrollo de procesos formativos continuados en las diversas áreas temáticas, que posibiliten dialogar, integrar y profundizar reflexiones sobre el PADRSs.
4. Cualificar el debate sobre nuestra concepción sindical, la identidad, el campo y el desarrollo, de la política pública, y la inclusión social, modos de producción y visión del mundo, democracia y participación ciudadana, organización sindical y acción política sindical.

En fin, la razón de ser de las propuestas es potenciar a las organizaciones sociales y a los movimientos. Como señala Batista (2010), el carácter pedagógico de los movimientos sociales se manifiesta en tres potencialidades: 1) pueden convertirse en matrices de otra forma de participación sociopolítica, cuyas perspectivas son el control directo de la vida social; 2) generan aprendizaje ciudadano; 3 ) constituyen sujetos creativos y transformadores de su realidad social.

\section{Principios pedagógicos}

Las propuestas educativas traducen sus concepciones y finalidades educativas a través de proposiciones y sentencias que buscan orientar la acción práctica de los educadores. A estas ideas clave las llamamos principios pedagógicos, que asumen la forma de una orientación general y que sirven a modo de pauta para la acción, sin llegar a ser prescriptivos. Así, por ejemplo, la Enfoc se afirma en los siguientes principios pedagógicos (Contag, 2006, p. 35):

1. Comprensión del ser humano en su totalidad.

2. Apertura a diferentes saberes, tanto disciplinares y profesionales, como culturales y artísticos.

3. Activación de la mística de la transformación social.

4. Articulación entre práctica y teoría.

5. Interdisciplinariedad e interculturalidad.

6. Formación pluralista crítica y creativa.

7. Perspectiva de acción transformadora.

8. Evaluación crítica permanente de acción y de la práctica formativa.

9. La investigación como principio educativo.

10. Construcción colectiva de conocimiento. 
11. Vivencia de relaciones horizontales y democráticas.

12. Fortalecimiento de las diferentes identidades: respeto a diferencias de raza/etnia, generación, género y región.

13. La memoria como potencial crítico transformador en la formación.

Aunque los bachilleratos populares no constituyen una unidad homogénea, Marina Ampudia (2007) plantea que pueden ser entendidos como un movimiento pedagógico que comparte algunos principios, como: 1) las escuelas surgen desde y con organizaciones del movimiento social; 2) la autogestión escolar y organizativa; 3) la educación popular emancipadora; 4) un proyecto político radical, y 5) las escuelas como organizaciones sociales.

Por su parte, el programa de acompañamiento comunitario de la Corporación Convivamos

posibilita relaciones entre los sujetos que ya no se basan en la transmisión de conocimientos sino en la horizontalidad y el respeto, genera iniciativas, autonomía y responsabilidad por los actos cotidianos; esto permite la construcción de sentidos emancipatorios, partiendo de la observación de la propia realidad, propiciando el reconocimiento de los factores individuales, familiares, sociales, estructurales, que comportan un mundo y un estar en ese mundo.(Convivamos, 2012, p. 27).

Vemos cómo, en todos los casos, hay principios pedagógicos comunes, como su articulación a los movimientos sociales, la formación integral de sujetos, el reconocimiento de su singularidad (étnica, generacional y de género), la autonomía y la autogestión, el diálogo de saberes (interepistémico), y la articulación entre teoría y práctica. También se reconoce el potencial formativo del propio movimiento, tanto en la formación de valores como la solidaridad y el compromiso, como en la adquisición de las capacidades propias de la acción colectiva (hablar en público, organizar reuniones, movilizarse, articularse, etcétera).

Por su parte, la Universidad indígena Amawtay Wasi, desde la singularidad de construcción de la propuesta educativa desde la cosmovisión ancestral andina, traduce sus principios pedagógicos en criterios metodológicos concretos expresados en verbos continuos:

1. Construyendo e imitando: vivenciando y experienciando. Desarrolla una adecuada forma de observación mediante la vivencia y experiencia directa con las comunidades.

2. Recuperando y reencantando: observando reflexivamente. Apunta a la necesidad de sistematizar y reflexionar lo vivenciado, lo experienciado, a fin de motivar la recuperación de la experiencia.

3. Significando y resignificando: conceptualizando y teorizando. Se propone significar y resignificar lo vivenciado, para lograr una aproximación reflexiva a lo que estamos trabajando.

4. Involucrándonos y comprometiéndonos: aplicando y experimentando. Tiene como finalidad cerrar el ciclo y se propone que el estudiante se involucre y comprometa con lo que está haciendo. La idea es aplicar lo aprendido, y experimentar a fin de evaluar su utilidad y potencialidad. (Sarango, 2009, p. 52).

\section{Construcción colectiva de currículos integrales y contextualizados}

Los sentidos políticos, los fines formativos y los principios pedagógicos de estas instituciones educativas alternativas se expresan en la definición de los contenidos formativos (conocimientos, valores, habilidades, capacidades o competencias) que se definen como valiosos para la formación de los educandos, sean individuales o colectivos. Esta selección de contenidos se expresa, en todos los casos, en sus currículos.

Es de destacar que en las cuatro experiencias analizadas los contenidos curriculares son construidos a través de mecanismos participativos que involucran a los educadores, a las comunidades y las poblaciones de base. En los casos de las universidades indígenas, la base de participación es amplia y comunitaria. En la Amawtay Wasi afirman que 
el camino propuesto va más allá de organizar una malla curricular que dé cuenta de actividades predeterminadas, de contenidos organizados de manera secuencial y coherente, está pensado como un proceso en construcción, contando con la participación de los diversos actores educativos directamente involucrados en el proceso de formación, desarrollo y aprendizaje. (Amawtay Wasi, 2004, p. 37).

En el caso de los bachilleratos populares, el programa curricular fue diseñado por los docentes y estudiantes de los diferentes bachilleratos a partir de instancias de trabajo colectivo, como jornadas, asambleas y comisiones de trabajo. Los resultados y la propuesta final fueron presentados bajo la condición de proyecto experimental a las secretarías educativas responsables de la supervisión de estas escuelas, tanto en el distrito de provincia de Buenos Aires como de capital federal.

Los contenidos de los cursos de la Enfoc también son construidos por los colectivos de educadores y representantes del movimiento sindical de trabajadores rurales. Esta construcción participativa de los contenidos de la nueva institucionalidad educativa conlleva a que estos respondan a las necesidades del movimiento y de las poblaciones y comunidades en las que van a desarrollarse.

Si asumimos que todo currículo es una selección de contenidos, decidida desde unos criterios políticos y pedagógicos, las propuestas educativas de los movimientos sociales se convierten en uno de los escenarios principales a través de los cuales pueden impulsar sus idearios políticos, sus apuestas organizativas y el tipo de sujetos (individuales y colectivos) que pretenden formar.

A diferencia de la educación oficial, fragmentada e insensible al contexto, los currículos construidos desde los movimientos sociales procuran ser coherentes con sus cosmovisiones y filosofía, integrales y contextualizados. El caso de la Universidad Amawtay Wasi es paradigmático: la definición de los componentes curriculares se basa en los elementos de la realidad: aire, fuego, tierra, agua y vida, a los cuales se incorporan cinco dimensiones formativas: yachay (saber), munay (amar), ruray (hacer), ushay (poder) y kawsay (origen, vida). La articulación de los cinco elementos y las cinco dimensiones da lugar a cinco centros de saber, cada uno con su desafío específico de formación:

1. Centro Yachay Munay: tiene por desafío las cosmovisiones y las racionalidades que articulan y organizan los saberes.

2. Centro Munay Ruray: su misión es posibilitar la emergencia del buen vivir.

3. Centro Ruray Ushay: su desafío es la recuperación de los ingenios humanos orientados a la vida, al reconciliar al hombre con la tecnología.

4. Centro Ushay Yachay: tiene como desafío la construcción de la interculturalidad.

5. Centro Kawsay: tiene como desafío la construcción de la sabiduría, que articula el conjunto de los centros del saber.

En los demás casos, hay referencia al desarrollo integral y complementario de diferentes dimensiones personales y colectivas. Así, en los bachilleratos populares se promueve una educación crítica, que integra diferentes capacidades de los estudiantes:

La formación integral cuenta con componentes educativos, laborales y artísticos, conforme a los principios de participación y autogestión, los cuales se desarrollan en espacios colectivos y cooperativos. Para ello, el proyecto educativo contempla diversas áreas del conocimiento, así como también la incorporación de un campo de formación de oficios. (Triana, 2012, p. 58).

Otro rasgo común es que los contenidos curriculares se abordan a partir de problemas, ejes o situaciones problemáticas relacionadas con sus propias realidades y prácticas. Esta perspectiva problematizadora se inscribe dentro de la tradición de la educación popular; el abordaje de los contenidos es activo, cuestionador de las verdades naturalizadas, generador de desafíos al pensamiento y a los saberes previos.

En estas propuestas educativas se le concede gran importancia a la formación en los valores propios de cada movimiento (autonomía, autogestión, solidaridad, dignidad, creatividad) y al desarrollo 
del pensamiento crítico. En la Enfoc y en los bachilleratos populares plantean favorecer la conciencia crítica y las capacidades prácticas relacionadas con los campos de acción del movimiento (cooperativismo, agroecología, derecho alternativo, educación popular, medicina y educación propia).

Salvo en los bachilleratos populares, que implican una gran presencialidad (todas las noches o fines de semana), en las otras propuestas educativas los contenidos se organizan en ciclos que combinan tiempos de presencialidad concentrada (cursos o encuentros de unas semanas o meses) con tiempos no presenciales, articulados a la vida cotidiana del movimiento y a los procesos comunitarios (Contag y Universidad Amawtay Wasi).

Como lo hemos evidenciado en anteriores investigaciones (Barragán et al., 2006), algunas acciones propias del movimiento, como las asambleas, las reuniones y las movilizaciones, también son consideradas constitutivas de la propuesta formativa. En los bachilleratos populares, las asambleas de cada grado y centro educativo constituyen uno de los ejes centrales de la formación política de estudiantes y educadores; en la Contag, todas sus actividades sindicales son consideradas formadoras de la "nueva sociabilidad"; en las universidades indígenas toda la vida comunitaria y sus acciones colectivas se asumen como prácticas educativas.

\section{Prácticas educativas y metodologías de trabajo}

Entendemos la metodología como el conjunto de orientaciones y criterios pedagógicos desde los cuales se desarrollan las prácticas educativas específicas (Torres, 2012). Tiene como referencia los principios pedagógicos, la modalidad formativa (curso, taller, clase), la singularidad de los sujetos educativos y los contextos específicos donde se desarrollan. En todos los casos, hay una preocupación permanente por la construcción teórica y práctica de la metodología de las propuestas.

En los cuatro casos, se da lugar preponderante al saber experiencial. Se promueven estrategias pedagógicas basadas en las prácticas de campo, en la construcción colectiva de conocimiento, en el diálogo de saberes. En las universidades indígenas se va más allá, al situarse en una perspectiva de pluralismo epistémico e interculturalidad, dado que, asumiendo la centralidad de sus propias cosmovisiones, integran del mundo "occidental" e incluso "oriental y africano" (Amawtay Wasi) conocimientos que juzgan pertinentes.

Se privilegian las estrategias participativas, dialógicas, de interpelación e interacción con la práctica y las realidades de los participantes. Muchos de los encuentros y sesiones asumen la forma de talleres, se realizan recorridos, caminatas y visitas extramuros. En los bachilleratos populares se han incorporado algunas innovaciones, como la cátedra compartida.

Como se señaló, los repertorios de acción colectiva se incorporan en la cotidianidad educativa, en la vida de los movimientos y en sus propuestas pedagógicas: las reuniones, las movilizaciones, las celebraciones y las asambleas son asumidas como un valioso espacio formativo que exige y potencia la participación. En la Enfoc, al igual que en los demás movimientos campesinos de Brasil, hablan de una "pedagogia do movimento" para referirse a los aprendizajes generados por el simple hecho de asociarse y movilizarse.

Algunas experiencias incorporan dispositivos simbólicos ("mística", rituales y eventos culturales), cuya preparación, desarrollo y ejecución son asumidos como educativos. En el caso de las universidades indígenas, valores y saberes se promueven a través de la relación con la naturaleza, y en los diferentes momentos y eventos de la vida comunitaria (el trabajo, las fiestas y demás celebraciones, y las movilizaciones).

\section{Sujetos y relaciones en la acción educativa}

En primer lugar, en todas las propuestas pedagógicas, la formación de sujetos y el establecimiento de relaciones horizontales ocupan un lugar central entre sus finalidades. En los bachilleratos populares se trata de formar sujetos políticos, que no se circunscribe únicamente a los espacios escolares, sino 
que involucra sus experiencias de la vida comunitaria y las organizaciones sociales:

No se trata de la educación reproductora de contenidos y estructuras de dominación, sino una instancia de configuración de sujetos capaces de asumir activamente la construcción de un orden por venir, esto es, como agentes de transformación social, protagonistas de su aprendizaje y constructores de nuevos horizontes. (Ampudia y Elisalde, 2014, p. 34).

Por otro lado, las representaciones de los sujetos educativos presentes en estas experiencias formativas son amplias. Involucran, por un lado, a los educandos y educadores como individuos de las prácticas formativas específicas; por otro lado, también son sujetos educativos otros actores sociales que inciden en los procesos educativos, como las comunidades y las organizaciones.

En la universidad indígena, se reconocen como sujetos educativos a las comunidades y sus autoridades. En los bachilleratos populares y en la Enfoc, los educadores y los propios centros asumidos como organizaciones populares son un sujeto colectivo decisivo en el proceso. En Convivamos, se reconocen como sujetos educativos a las personas, los colectivos y las organizaciones comunitarias, al igual que los espacios de articulación asociativa y la comunidad en su conjunto. En todas las experiencias, el gran sujeto educando y educador es el propio movimiento o proceso organizativo, pues su dinámica y acción colectiva son formativas, a la vez que los procesos formativos lo fortalecen.

Todas las propuestas promueven relaciones horizontales y democráticas, tanto en los eventos formativos específicos como en todo el proceso de las escuelas y universidades. En todas hay instancias de deliberación y toma de decisiones de democracia directa, como las asambleas, los encuentros y los cabildos. El caso de los bachilleratos populares es representativo, pues tiene como uno de sus principales principios políticos y pedagógicos la autogestión. En cuanto a las relaciones y procesos democráticos, Marina Ampudia (citada en Triana, 2012, p. 57) señala:
La asamblea como dispositivo que propicia la participación, de la voz de los que no tienen voz, como dicen algunos, de los que sólo pueden gritar, habilita la posibilidad de la voz y la asamblea es una característica de la organización que lo impulsa y es una característica del bachillerato impulsado por esa organización. Allí participan docentes y estudiantes, y se resuelve el quehacer en su multiplicidad, el quehacer de un espacio social construido colectivamente... desde abajo para arriba.

Otras prácticas que confirman el carácter participativo y horizontal de las propuestas educativas son la docencia colegiada (bachilleratos), los recorridos por el territorio (Amawtay Wasi y Convivamos), los conversatorios, tertulias y otros espacios conversacionales, las pasantías y los emprendimientos comunitarios (Contag y Amawtay Wasi).

Desde un comienzo, los bachilleratos populares se definieron como escuelas autogestionadas, populares, públicas y no estatales. El desarrollo de experiencias educativas en el marco de la educación formal, pero gestionadas por organizaciones sociales, complejizó la discusión sobre el carácter de lo público no estatal, con lo cual se desmarcó y criticó la versión neoliberal de que toda la educación es pública, aun cuando su carácter sea privado (Sverdlick, citada en Triana, 2012).

Finalmente, podemos reconocer una comprensión de las relaciones entre las personas que participan en los procesos sociales y educativos, sustentada en una "ética de la alteridad". Así, por ejemplo, en la Corporación Convivamos se parte de comprender al otro como un sujeto, es decir, como un ser humano que deja de ocupar un lugar pasivo en la sociedad, para convertirse en un ser independiente, autónomo y activo, constructor de la historia, por ende, de la transformación (Corporación Convivamos, 2012, p. 22).

\section{Investigación y producción de conocimiento pedagógico}

Estas propuestas educativas generan espacios y momentos de reflexión pedagógica sobre los procesos y proyectos educativos. El desafío de construir otra 
educación y una alternativa pedagógica ha llevado a que los equipos de docentes y de coordinación de las propuestas destinen parte de su tiempo a evaluar, reflexionar y sistematizar sus experiencias, con el propósito de ir produciendo cambios a lo largo de los procesos formativos, y de generar el conocimiento pedagógico que dará la sostenibilidad y la coherencia a las propuestas.

Las investigaciones (sean diagnósticos, sistematizaciones u otras formas de producción de conocimiento) también son consideradas experiencias educativas. Incluso, en las universidades indígenas se incorpora dentro del currículo tanto la formación en producción sistemática de conocimientos, como el intercambio con otros conocimientos y con otros investigadores provenientes de otros movimientos y culturas, como los de afroamericanos y los ambientalistas.

En el caso de la Enfoc, entre el 2010 y el 2012 ha realizado tres sistematizaciones de su experiencia pedagógica (Contag, 2010; Contag, 2011; Contag, 2012), en las cuales se ha preguntado sobre la experiencia de los dirigentes sindicales, los colectivos sindicales y los educadores que participan de la escuela; en este caso, la producción permanente de conocimiento sobre la experiencia se ha incorporado como una práctica permanente de la Escuela Sindical.

La investigación en la Universidad Amawta Wasi es considerada una herramienta que contribuye a la creación de pensamiento propio e intercultural, en la medida en que potencia la recuperación y revitalización de lenguas autóctonas, la protección de la madre tierra y la recuperación ambiental, y la enseñanza y recuperación de la historia; tanto los estudiantes (para graduarse) como los equipos de educadores realizan investigaciones significativas para el movimiento indígena y su proyecto cultural.

La alianza entre los bachilleratos populares articulados en la coordinadora y la CEIP, conformada por profesores y estudiantes de la Universidad de Buenos Aires, ha posibilitado la realización de varias investigaciones sistemáticas, como diagnósticos e investigaciones participativas y cartografías sociales. Esta última es una herramienta de visibilidad y desfragmentación del espacio social donde se localiza el bachillerato, y eso es tomado por numerosos bachilleratos para desplegarse y representar el espacio social de inserción/acción con sus organizaciones populares y en sus comunidades (Ampudia y Elisalde, 2014, p. 33).

\section{Sostenibilidad de las propuestas educativas}

Un aspecto importante de las propuestas educativas de los movimientos sociales es su sostenibilidad, la cual trasciende la capacidad de conseguir recursos económicos para garantizar la continuidad de sus acciones pedagógicas, e involucra otras capacidades como (Aguilera y González, 2014, pp. 121-ss):

1. La capacidad de generar vínculos firmes y estables con las bases sociales. Esta es una fortaleza de las propuestas educativas porque ubica, en el vínculo comunitario, la potencia para sostener, mantener y dar continuidad a los movimientos sociales que las secundan. En este vínculo se forman las bases para integrarlas a las acciones del movimiento asumiendo procesos de liderazgo. De manera que las experiencias privilegian y propenden porque sus estudiantes sean del territorio o de la comunidad, tengan algún tipo de vínculo, en algunos casos que realicen trabajo en ella, $o$ que, con la formación que reciban, se proyecten para ofrecer sus conocimientos a los demás.

2. Capacidad de establecer articulaciones con otras organizaciones y movimientos. Para desarrollar sus proyectos educativos, establecen redes y alianzas tanto con otros movimientos sociales y educativos similares, como con universidades, agencias de cooperación, con ong o con colectivos de intelectuales comprometidos, sin perder autonomía. Existe una red continental de universidades indígenas a las que está afiliada la Amawtay Wasi; la Contag forma parte de redes de organizaciones campesinas en el marco de Unasur y en el 2012 se afilió al Consejo de Educación Popular de América Latina y el Caribe (CEAAL); la coordinadora de bachilleratos populares 
recibe respaldo permanente de la Cooperativa de Educadores e Investigadores, a su vez incorporada a la Red de Investigadores y Organizaciones Sociales de América Latina (Riosal), recientemente afiliada al Consejo Latinoamericano de Ciencias Sociales (Clacso).

3. Capacidad de generar u obtener recursos económicos para sostener las propuestas. $\mathrm{La}$ magnitud de las iniciativas formativas de los movimientos implica un ingente flujo de recursos. Las estrategias para obtenerlos varía de organización a organización: la Enfoc es financiada por la Contag, la cual a su vez obtiene recursos externos para los eventos formativos; los bachilleratos populares parten de la autogestión organizativa, pero algunos de ellos reivindican y han logrado el pago de salario a sus profesores; la universidad indígena es respaldada por el movimiento indígena y la Conaie, pero además buscó apoyos de financiación provenientes de agencias de cooperación; estas últimas también apoyan algunos de los programas de Convivamos, aunque también lo han logrado a partir de los proyectos y planes participativos locales.

\section{Balance: tensiones que atraviesan las propuestas educativas}

Para terminar, se señalarán algunas tensiones presentes en la construcción pedagógica de las propuestas, las cuales también atraviesan a los propios movimientos sociales, con quienes comparten su cuestionamiento al orden dominante, y sus visiones de futuro y valores emancipadores. Por ello, en las experiencias analizadas encontramos varias tensiones entre lo instituido dentro de las sociedades $y$ el mundo escolar que pretenden cuestionar, y lo instituyente, que puja por incorporar nuevos vínculos, prácticas, valores y significados sociales.

Lo primero que llama la atención es que todas las propuestas asuman denominaciones propias de la educación institucionalizada: escuelas, bachilleratos, universidades. En el primer caso, dentro de la tradición sindical, la Enfoc asume la escuela como estrategia formativa formalizada, más orgánica, que contrasta con otros eventos educativos puntuales y aislados. En el caso de los bachilleratos, toman este nombre porque desde su opción política asumen la educación como un derecho, en este caso derecho a la educación media, solo que tales instituciones son agenciadas por colectivos de educadores que las conciben como "organizaciones sociales". Las universidades indígenas, al igual que las llamadas universidades obreras de la primera mitad del siglo xx, la Universidad de las Madres de Plaza de mayo y la recientemente creada Universidad de los Trabajadores en Buenos Aires, asumen esta denominación dentro de su propósito de alcanzar un reconocimiento estatal para la formación que allí ofrecen.

No obstante, el hecho de compartir el nombre no ha significado que compartan su sentido y papel predominante dentro de las sociedades contemporáneas. En todos los casos existe el explícito propósito de cuestionar su papel reproductor e integrador al orden imperante y de atribuirle fines políticos y educativos alternativos.

De una manera u otra se proponen cuestionar los valores y conocimientos hegemónicos, fortalecer los movimientos sociales (asumidos como anticapitalistas) y formar sujetos con vocación de transformación social y cultural. En consecuencia, en las cuatro propuestas se asumen formas de organización y de gestión educativa radicalmente diferentes a las predominantes en este tipo de instituciones: coordinación colegiada, instancias asambleístas, redes y relaciones fluidas con las poblaciones y comunidades de base, contenidos y prácticas evaluativas propias, etcétera.

En fin, podemos afirmar que estas propuestas educativas se colocan intencionalmente en los bordes del sistema educativo: sin salirse de él, lo desbordan con lo que ponen en evidencia sus límites. Esta condición de "frontera" o liminal, que les permite no considerarse ni "adentro" del sistema pero tampoco "afuera" de él, les permite relacionarse con el Estado para exigir el cumplimiento de sus obligaciones con respecto "al derecho a la educación" y al "reconocimiento de estas nuevas institucionalidades", $y$, a la vez, propugnar por el ejercicio de su autonomía y la autogestión de los procesos educativos que agencian. 
Esta condición fronteriza conlleva tensiones con el orden institucional, en particular con las instancias gubernamentales responsables de las políticas educativas. Así, por ejemplo, las dos universidades han tenido dificultades para ser reconocidas o acreditadas como instituciones de educación superior; por su parte, los bachilleratos populares han luchado desde sus inicios (con éxito) para que se les reconozca la facultad de expedir certificados válidos, y para que a los educadores se los reconozca como trabajadores de la educación (con logros parciales).

Dada la singularidad de los últimos gobiernos del Partido de los Trabajadores (РT), la Contag ha logrado, junto con otras organizaciones campesinas, influir en la definición de la política de educación "do campo" y la Escuela obtiene parte de su financiación a través del Estado. La tendencia común es la de afirmar autonomía en la gestión y orientación de las propuestas educativas, y exigencia de la responsabilidad gubernamental de financiar o respaldar la educación.

\section{Referencias}

Aguilera, A. y González, M. I. (2014). Educación y movimientos sociales. La sostenibilidad de las propuestas. Revista Folios, (39), pp. 117-135.

Aguilera, A., González, M. I. y Torres, A. (2014). Investigar subjetividades y formación de sujetos con organizaciones y movimientos sociales pp. 49-70. En C. Piedrahita et al., Acercamientos metodológicos a la subjetivación política: debates latinoamericanos, Buenos Aires: Clacso.

Ampudia, M. (2007). El sujeto de la educación para jóvenes y adultos. Territorialización y desterritorialización de la periferia. Buenos Aires: CEIP.

Ampudia, M. (2012). Movimientos sociales y educación popular. Reflexiones sobre la experiencia educativa de los bachilleratos populares. OSERA, (6), pp. 1-15.

Ampudia, M. y Elisalde, R. (2014). Los bachilleratos populares en la Argentina: Organizaciones sociales y movimiento pedagógico. Revista Educación y Cultura, (105), pp. 28-33.

Barragán, D., Mendoza, N. y Torres, A. (2006). Aquí todo es educativo. Saberes pedagógicos y prácticas formativas en organizaciones populares. Folios, (23), pp. 15-28.
Batista, M. S. (2010). Movimentos sociais e educação popular do campo. Reconstituindo território e identidade camponesa, pp. 169-190. En E. Jezine y M. L. de Almeida (eds.), Educação e movimentos sociais. Campinas: Alínea.

Colectivo Diatriba. (2013). Los bachilleratos populares: pedagogía de la osadía. Diatriba (3). Revista de pedagogía militante. Santiago de Chile, Chile.

Contag. (2006). Proyecto políticopedagógico. Brasilia: Contag.

Contag. (2010). Enfoc: repercusiones de una manera de ser escuela. Brasilia: Enfoc/Contag.

Contag. (2011). Almanaque Enfoc: um fazer de muitas mãos. Brasilia: Contag.

Contag. (2012). Multiplicação criativa, um entrelaçar de práticas e saberes. Brasilia: Enfoc/Contag.

Corporación Convivamos. (2011). Plan trienal 20112013. Medellín: Corporación Convivamos.

Corporación Convivamos. (2012). Cuadernos Convivamos. Acompañamiento comunitario. Nuestra labor pedagógica y de transformación social. Medellín: Corporación Convivamos.

Sarango, L. (2009). Universidad intercultural de las nacionalidades y pueblos indígenas "Amawtay Wasi". Ecuador/Chinchaysuyu, p. 191-214. En D. Mato (coord.), Instituciones interculturales de educación superior en América Latina. Procesos de construcción, logros, innovaciones y desafíos. Caracas: Iesalc-Unesco.

Sverdlick, I. y Costas, P. (2008). Bachilleratos populares en empresas recuperadas y organizaciones sociales en Buenos Aires-Argentina. Buenos Aires, Laboratorio de políticas públicas.

Torres Carrillo, A. (1995). Educación y pedagogía en las experiencias organizativas populares. La Piragua. Revista latinoamericana y caribeña de educación y política, (1), pp. 49-54.

Torres Carrillo, A. (2012). El potencial emancipatorio de la educación popular como práctica política y pedagógica. La Piragua. Revista latinoamericana y caribeña de educación y política, (37), pp. 59-74.

Triana, D. (2012). Autonomía y autogestión, un horizonte político pedagógico. Los bachilleratos populares en Buenos Aires 2001-2012 (tesis inédita de maestría). Universidad Pedagógica Nacional, Bogotá, Colombia.

Universidad Intercultural de Nacionalidades y Pueblos Indígenas, Amawtay Wasy (2004). Sumak Yachaypi, Alli Kawsay pipash yaCHAKUNA. Aprender en la sabiduría y el buen vivir. Learning Wisdom and the Good to Live. Quito: Unesco.

Para citar este artículo

Torres, A. (2017). Prácticas educativas en movimientos sociales de América Latina. Folios, (46), 3-14. 